\title{
Grasas Saturadas y Salud
}

\author{
Alexis Lama \\ Cardiólogo Clínica Integramédica
}

Señor Editor:

Desde hace años, numerosos estudios han mostrado que la ingesta de grasas saturadas no es nociva para el desarrollo de las enfermedades cardíacas e, incluso, tendrían un efecto beneficios contra el accidente vascular. Recientemente, una nueva publicación señala que la reducción del consumo de grasas saturadas no se traduce en efecto beneficioso sobre la morbilidad cardiovascular y la mortalidad total, proponiendo una reevaluación de las actuales recomendaciones de la Guías Dietéticas Americanas de un consumo de grasas saturadas $<10 \%$ de las calorías totales. Los autores de esta publicación, provenientes de universidades de Dinamarca, EE.UU. y Canadá, algunos de ellos con conflictos de intereses declarados con Fundaciones relacionadas a la industria láctea, enfatizan los efectos saludables del consumo de leche entera, aparte de huevo, carne no procesada y chocolate negro ${ }^{1}$. Creo que es necesario comentar algunos aspectos de la específica recomendación de consumir leche entera en la citada publicación, reconociendo en primer término que el tema es controvertido, teniendo en cuenta que la variedad de tipos de leche y sus productos, en los diferentes estudios es muy amplia y puede explicar, en gran parte, los resultados contradictorios obtenidos en los diversos estudios publicados. Muchos autores defienden la idea de reducir su consumo al mínimo. Aparte de contener el disacárido lactosa (cuya intolerancia puede alcanzar una prevalencia $>45 \%$ en nuestro medio), la leche tiene D- galactosa, monosacárido constituyente de la lactosa, que en estudios experimentales ha mostrado efectos deletéreos para la salud, produciendo cambios semejantes al envejecimiento ${ }^{2}$. Algunos autores, como Hiromi Shinya, pionero de la cirugía endoscópica en EEUU, piensa definitivamente que la leche es un mal alimento para el adulto, debido a que la grasa que contiene es oxidada por el proceso de pasteurización, la que también destruye sus enzimas, y que su uso favorecería la inflamación. Su alto contenido de caseína hace que, inmediatamente que llega al estómago, forme grumos que hacen muy difícil su digestión. También señala en su libro que el consumo excesivo de leche causa osteoporosis en vez de prevenirla, debido a que la rápida absorción de calcio, con la consecuente elevación súbita de la calcemia, produce un aumento de la excreción de calcio a través de la orina, en un intento del organismo de retornar a lo normal el nivel anormal alcanzado con la ingesta de leche ${ }^{3}$. También, el renombrado científico Colin Campbell considera, como fruto de sus extensas investigaciones, que la leche de vaca no debe consumirse, ya que es un alimento dañino para las personas ${ }^{4}$. La caseína que contiene, que constituye el $85 \%$ de la proteína de la leche de vaca, fomenta las etapas del proceso cancerígeno y la cataloga como el carcinógeno más potente que se haya identificado, aparte que se ha demostrado que su consumo aumenta el riesgo de cáncer de próstata ${ }^{5}$.

Considérese que la caseína de la leche de vaca tiene fundamentalmente dos formas: la llamada A1 y la A2, dependiendo del tipo de vaca ${ }^{6}$. La caseína A1 es la dañina, y dado que la industria 
láctea usa las vacas que dan más leche -la raza Holstein- alrededor del $90 \%$ de las vacas de las explotaciones lecheras son de este tipo, cuya leche contiene fundamentalmente caseína tipo A1. Evidencias epidemiológicas afirman que el consumo de este tipo de leche, con beta-caseína A1, se asocia como un factor de riesgo para diabetes tipo 1, enfermedad coronaria, arteriosclerosis, síndrome de muerte súbita infantil, autismo y esquizofrenia. Una amplia gama de estudios de investigaciones estadounidenses y europeas ha demostrado una reducción en los síntomas de autismo y esquizofrenia con una disminución en la ingesta de leche A1. Además, los ensayos en animales también han respaldado la vinculación de la diabetes tipo 1 con la exposición a la leche en general y A1 beta-caseína en particular ${ }^{7}$. Además, téngase en cuenta un metanálisis procedente de China, que comprendió siete estudios, que señala una asociación de tipo lineal dosis - respuesta, entre el consumo diario de productos lácteos, especialmente de leche de vaca, con un mayor riesgo de enfermedad de Parkinson ${ }^{8}$. Otro estudio, controvertido, realizado en Suecia, de diseño observacional y que como todos los de su tipo, no permite establecer causalidad, concluye que el consumo de leche se asoció a mayor riesgo de mortalidad y de fracturas óseas ${ }^{9}$. Por todas estas razones, me parece prudente tomar con precaución la recomendación de promover el uso de leche entera de vaca, mientras no exista mayor evidencia de su beneficio para la salud. Mientras, tal vez sea más beneficioso el consumo de productos distintos a la leche de vaca o de sus derivados directos, como la leche y derivados de oveja y/o de cabra, como también el consumo de leche fermentada de manera natural, es decir el yogur, así como el consumo de la llamada mantequilla clarificada o "ghee", pilar de la medicina milenaria de la India, que no contiene caseína ni lactosa, y que está compuesta, principalmente, de ácidos grasos de cadena media, especialmente ácido butírico, que posee efectos positivos sobre la función inmunológica, la inflamación y el perfil lipídico.

\section{Referencias}

1. ASTRUP A, MAGKOS D, BIER J, et al. Saturated Fats and Health: A Reassessment and Proposal for Food-based Recommendations: JACC State-of -the-Art Review. JACC 2020 (Disponible en línea el 17 de junio de 2020.

2. CUI X, ZUO P, ZHANG Q, et al. Chronic systemic D-galactose exposure induces memory loss, neurodegeneration, and oxidative damage in mice: protective effects of R-alpha-lipoic acid. J Neurosci Res. 2006; 84(3):647-654.

3. SHINYA H. The Enzyme Factor. Millichap Books, 2010.

4. CAMPBELL C. Estudio de China, Editorial Sirio, 2012.

5. PARK S, KIM J, KIM Y, el al. A milk protein, casein, as a proliferation promoting factor in prostate cancer cells. World J Mens Health. 2014; 32(2):76-82.
6. WINTERS N. La estrategia metabólica contra el cáncer. Editorial edaf, 2018.

7. LAUGESEN M, ELLIOTT R. Ischaemic heart disease, Type 1 diabetes, and cow milk A1 beta-casein. N Z Med J. 2003; 116(1168):U295

8. JIANG W, JU C, JIANG H, ZHANG D. Dairy foods intake and risk of Parkinson's disease: a dose-response meta-analysis of prospective cohort studies. Eur J Epidemiol. 2014; 29(9):613-619.

9. MICHAËLSSON K, WOLK A, LANGENSKIÖLD S, et al. Milk intake and risk of mortality and fractures in women and men: cohort studies. BMJ 2014; 349:g6015. 